International Journal of Pure and Applied Mathematics

Volume 86 No. 5 2013, 811-818

ISSN: 1311-8080 (printed version); ISSN: 1314-3395 (on-line version)

url: http://www.ijpam.eu

doi: http://dx.doi.org/10.12732/ijpam.v86i5.5

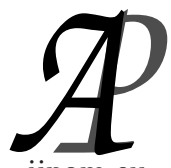

ijpam.eu

\title{
NEW EFFICIENT ALGORITHMS FOR MINIMIZATION OF NON-LINEAR FUNCTIONS
}

\author{
K. Karthikeyan \\ Mathematics Division \\ School of Advanced Sciences \\ VIT University, Vellore-14, Tamil Nadu, INDIA
}

\begin{abstract}
In this paper, we suggest two new algorithms for minimization of nonlinear functions. Then the comparative study of the new algorithms with the Newton's algorithm is established by means of examples.
\end{abstract}

AMS Subject Classification: 90C27, 93B40, 65K10

Key Words: Newton's algorithm, Jarratt's method, order of convergence

\section{Introduction}

Optimization problems with or without constraints arise in various fields such as science, engineering, economics, management sciences, etc., where numerical information is processed. An unconstrained minimization problem is the one where a value of the vector $\mathrm{x}$ is sought that minimizes the objective function $f(x)$. This problem can be considered as particular case of the general constrained non-linear programming problem. Several methods (see for example [7], [8], [10], [11]) are available for solving unconstrained minimization problems. Coppe (see [3]) proposed a two-stage feasible directions algorithm for nonlinear constrained optimization. Newton's method (see [12]) is used for

Received: April 6, 2013

(c) 2013 Academic Publications, Ltd. url: www.acadpubl.eu 
various classes of optimization problems, such as unconstrained minimization problems, equality constrained minimization problems.

Many iterative methods have been developed to find a simple root of a nonlinear equation $f(x)=0$ such as Newton's method and its variants, Secant method, Halley's method, Chebychev method and Jarratt's method (see [6]) and many researchers developed efficient modifications of Newton's method (see [1], [4]) and others on variants of Chebyshev-Halley's method free from second derivative. Hou et al (see [5]) presented a new twelfth order family of methods which improves an eighth order method, see [1]. Several efficient modifications of Jarratt's method have been developed and applied in [2], [4], [9], [13] to improve the order of convergence. Recently Young-II kim and Changbum Chun (see [14]) introduced modification of Jarratt's method for solving nonlinear equation with the comparative study of the new iterative method with Newton's Algorithm, Jarratt's method and Hou-Li method. In this paper, we suggest two new algorithms for minimization of nonlinear functions. Then, we present the comparative study among the new algorithms and Newton's algorithm.

\section{New Algorithm}

Consider the nonlinear optimization problem: Minimize $\{f(x), x \in R, f: R \rightarrow$ $R\}$ where $f$ is a nonlinear twice differentiable function. Consider the function $G(x)=x-\left(g(x) / g^{\prime}(x)\right)$ where $g(x)=f^{\prime}(x)$. Here $f(x)$ is the function to be minimized. $G^{\prime}(x)$ is defined around the critical point $x^{*}$ of $f(x)$ if $g^{\prime}\left(x^{*}\right)=$ $f^{\prime \prime}\left(x^{*}\right) \neq 0$ and is given by $G^{\prime}(x)=g(x) g^{\prime \prime}(x) / g^{\prime}(x)$. If we assume that $g^{\prime \prime}\left(x^{*}\right) \neq$ 0 , we have $G^{\prime}\left(x^{*}\right)=0$ iff $g\left(x^{*}\right)=0$. Consider the equation

$$
g(x)=0
$$

whose one or more roots are to be found. $y=g(x)$ represents the graph of the function $g(x)$ and assume that an initial estimate $x_{0}$ is known for the desired root of the equation $g(x)=0$.

\subsection{New Method-I}

We introduce new method-I which is based on Jarrat's method (see [10]) for $g(x)$ and given by

$$
x_{n+1}=x_{n}-J_{g}\left(x_{n}\right) \frac{g\left(x_{n}\right)}{g^{\prime}\left(x_{n}\right)} \text { where } J_{g}\left(x_{n}\right)=\frac{3 g^{\prime}\left(y_{n}\right)+g^{\prime}\left(x_{n}\right)}{6 g^{\prime}\left(y_{n}\right)-2 g^{\prime}\left(x_{n}\right)}
$$


and $y_{n}=x_{n}-\frac{2 g\left(x_{n}\right)}{3 g^{\prime}\left(x_{n}\right)}$ whose order of convergence is four.

New Algorithm-I. Since $g(x)=f^{\prime}(x)$, the equation (2) becomes

$$
x_{n+1}=x_{n}-J_{f^{\prime}}\left(x_{n}\right) \frac{f^{\prime}\left(x_{n}\right)}{f^{\prime \prime}\left(x_{n}\right)} \text { where } J_{f^{\prime}}\left(x_{n}\right)=\frac{3 f^{\prime \prime}\left(y_{n}\right)+f^{\prime \prime}\left(x_{n}\right)}{6 f^{\prime \prime}\left(y_{n}\right)-2 f^{\prime \prime}\left(x_{n}\right)}
$$

and $y_{n}=x_{n}-\frac{2 f^{\prime}\left(x_{n}\right)}{3 f^{\prime \prime}\left(x_{n}\right)}$ whose order of convergence is also four.

\subsection{New Method-II}

Several efficient modifications of Jarrat's method have been developed and applied to improve the order of convergence. Young-II kim and Changbum Chun (see [14]) introduced a new twelfth order modifications version of Jarrat's method for solving nonlinear equations. Here in this section, we introduce new algorithm-II which is based on the above method. From the equation (2) let we have

$$
z_{n}=x_{n}-J_{g}\left(x_{n}\right) \frac{g\left(x_{n}\right)}{g^{\prime}\left(x_{n}\right)}
$$

Using an elementary calculation, the circle of curvature at $\left(z_{n}, g^{\prime}\left(z_{n}\right)\right)$ found to be

$$
\begin{gathered}
\left(x-z_{n}+\frac{g^{\prime}\left(z_{n}\right)\left[1+g^{\prime}\left(z_{n}\right)^{2}\right]}{g^{\prime \prime}\left(z_{n}\right)}\right)^{2}+\left(y-g\left(z_{n}\right)-\frac{1+g^{\prime}\left(z_{n}\right)^{2}}{g^{\prime \prime}\left(z_{n}\right)}\right)^{2} \\
=\frac{\left(1+g^{\prime}\left(z_{n}\right)^{2}\right)^{3}}{g^{\prime \prime}\left(z_{n}\right)^{2}}
\end{gathered}
$$

At the intersection point $\left(x_{n+1}, 0\right)$ of the above equation (5) with the $\mathrm{x}$-axis, we get

$$
\begin{aligned}
\left(x_{n+1}-z_{n}\right)^{2}+ & 2 \frac{g^{\prime}\left(z_{n}\right)\left(1+g^{\prime}\left(z_{n}\right)^{2}\right)}{g^{\prime \prime}\left(z_{n}\right)}\left(x_{n+1}-z_{n}\right)+g\left(z_{n}\right)^{2} \\
& +2 g\left(z_{n}\right) \frac{\left(1+g^{\prime}\left(z_{n}\right)^{2}\right)}{g^{\prime \prime}\left(z_{n}\right)}=0
\end{aligned}
$$

Equation (5) can further be rewritten as follows

$$
x_{n+1}=z_{n}-\frac{g\left(z_{n}\right)^{2}+2 g\left(z_{n}\right) \frac{1+g^{\prime}\left(z_{n}\right)^{2}}{g^{\prime \prime}\left(z_{n}\right)}}{x_{n+1}-z_{n}+2 \frac{g^{\prime}\left(z_{n}\right)\left(1+g^{\prime}\left(z_{n}\right)^{2}\right)}{g^{\prime \prime}\left(z_{n}\right)}}
$$

By replacing $x_{n+1}$ on the right hand side of (7) by the Newton iterate, we have

$$
x_{n+1}=z_{n}-\frac{g^{\prime}\left(z_{n}\right) g^{\prime \prime}\left(z_{n}\right) g\left(z_{n}\right)^{2}+2 g^{\prime}\left(z_{n}\right) g\left(z_{n}\right)\left(1+g^{\prime}\left(z_{n}\right)^{2}\right)}{2 g^{\prime}\left(z_{n}\right)^{2}\left(1+g^{\prime}\left(z_{n}\right)^{2}\right)-g\left(z_{n}\right) g^{\prime \prime}\left(z_{n}\right)}
$$


To derive its second derivative free variant, let us consider the following approximation

$$
g^{\prime \prime}\left(z_{n}\right) \approx \frac{g^{\prime}\left(w_{n}\right)-g^{\prime}\left(z_{n}\right)}{w_{n}-z_{n}} \quad \text { where } w_{n}=z_{n}-\frac{g\left(z_{n}\right)}{g^{\prime}\left(z_{n}\right)}
$$

The equation (8) becomes

$$
x_{n+1}=z_{n}-\frac{g\left(z_{n}\right)\left[2+3 g^{\prime 2}\left(z_{n}\right)-g^{\prime}\left(z_{n}\right) g^{\prime}\left(w_{n}\right)\right]}{g^{\prime}\left(z_{n}\right)+2 g^{\prime 2}\left(z_{n}\right)+g^{\prime}\left(w_{n}\right)}
$$

By replacing the first term of $(6),\left(x_{n+1}-z_{n}\right)^{2}$ with $\left(\frac{g\left(z_{n}\right)}{g^{\prime}\left(z_{n}\right)}\right)^{2}$ from Newton's iterate results the following

$$
x_{n+1}=z_{n}-\frac{g\left(z_{n}\right)^{2} g^{\prime \prime}\left(z_{n}\right)+2 g\left(z_{n}\right) g^{\prime}\left(z_{n}\right)^{2}}{2 g^{\prime}\left(z_{n}\right)^{3}}
$$

By using the approximation defined by (9), we obtain the second derivative free variant of (11)

$$
x_{n+1}=z_{n}-\frac{1}{2}\left(3-\frac{g^{\prime}\left(w_{n}\right)}{g^{\prime}\left(z_{n}\right)}\right) \frac{g\left(z_{n}\right)}{g^{\prime}\left(z_{n}\right)}
$$

New Algorithm-II. Since $g(x)=f^{\prime}(x)$, the above equation (12) becomes

$$
x_{n+1}=z_{n}-\frac{1}{2}\left(3-\frac{f^{\prime \prime}\left(w_{n}\right)}{f^{\prime \prime}\left(z_{n}\right)}\right) \frac{f^{\prime}\left(z_{n}\right)}{f^{\prime \prime}\left(z_{n}\right)}
$$

The convergence analysis of the equation (13) is defined by the following theorem.

\section{Convergence Analysis}

Theorem 1. Assume that the function $g: D \subset R \rightarrow R$ for an open interval $D$ has a simple root $x^{*}$ in $D$. If $f(x)$ is sufficiently smooth in a neighborhood of the root $x^{*}$, then the method given by (12) is of order twelve.

Proof. The proof of this theorem follows as in convergence theorem (see [14]) and hence the order of convergence of the algorithm (13). 


\section{Numerical Illustrations}

Example 4.1. Consider the function $f(x)=x e^{x}-1, x \in R$. Then, minimizing point of the function is equal to -1 which is obtained in 7 iterations by Newton's algorithm, in 3 iterations by New Algorithm-I and in 2 iterations by New Algorithm-II for the initial value $x_{0}=1$ and also seen the variation in iterations for the initial value of $x_{0}=2$ and $x_{0}=3$. The results of the Example 4.1 are shown in the tables 1-3.

\begin{tabular}{|c|c|c|c|}
\hline Iterations & Newton's algorithm & New Algorithm-I & New Algorithm-II \\
\hline 0 & 1.000000 & 1.000000 & 1.000000 \\
1 & 0.333333 & -0.377329 & -0.853119 \\
2 & -0.238095 & -0.970322 & -1.000000 \\
3 & -0.670528 & -1.000000 & \\
4 & -0.918350 & & \\
5 & -0.993836 & & \\
6 & -0.999962 & & \\
7 & -1 & & \\
\hline
\end{tabular}

Table 1

\begin{tabular}{|c|c|c|c|}
\hline Iterations & Newton's algorithm & New Algorithm-I & New Algorithm-II \\
\hline 0 & 2.000000 & 2.000000 & 2.000000 \\
1 & 1.250000 & 0.358414 & -0.383209 \\
2 & 0.557692 & -0.740017 & -0.999950 \\
3 & -0.051330 & -0.998443 & -1.000000 \\
4 & -0.538159 & -1.000000 & \\
5 & -0.854409 & & \\
6 & -0.981421 & & \\
7 & -0.999661 & & \\
8 & -0.999999 & & \\
9 & -1.000000 & & \\
\hline
\end{tabular}

Table 2

Example 4.2: Consider the function $f(x)=x^{5}+x^{4}+4 x^{2}-15, x \in R$. Then, minimizing point of the function is equal to 0 which is obtained in 6 iterations by Newton's algorithm, 3 iterations by New Algorithm-I and in 2 iterations by New Algorithm-II for the initial value $x_{0}=2$ and also seen the 


\begin{tabular}{|c|c|c|c|}
\hline Iterations & Newton's algorithm & New Algorithm-I & New Algorithm-II \\
\hline 0 & 3.000000 & 3.000000 & 3.000000 \\
1 & 2.200000 & 1.201916 & 0.306123 \\
2 & 1.438095 & -0.241894 & -0.983696 \\
3 & 0.728954 & -0.946118 & -1.000000 \\
4 & 0.095395 & -0.999996 & \\
5 & -0.427368 & -1.000000 & \\
6 & -0.791491 & & \\
7 & -0.964025 & & \\
8 & -0.998751 & & \\
9 & -0.999999 & & \\
10 & -1.000000 & & \\
\hline
\end{tabular}

Table 3

variations in iteration for the initial value of $x_{0}=3$ and $x_{0}=1$. The results of the Example 4.2 are shown in the tables 4-6.

\begin{tabular}{|c|c|c|c|}
\hline Iterations & Newton's algorithm & New Algorithm-I & New Algorithm-II \\
\hline 0 & 1.000000 & 1.000000 & 1.000000 \\
1 & 0.575000 & 0.095748 & 0.000276 \\
2 & 0.200420 & 0.000000 & 0.000000 \\
3 & 0.010252 & & \\
4 & 0.000001 & & \\
5 & 0.000000 & & \\
\hline
\end{tabular}

Table 4

\begin{tabular}{|c|c|c|c|}
\hline Iterations & Newton's algorithm & New Algorithm-I & New Algorithm-II \\
\hline 0 & 2.000000 & 2.000000 & 2.000000 \\
1 & 1.407407 & 0.843329 & 0.314838 \\
2 & 0.927224 & 0.001797 & 0.000000 \\
3 & 0.509766 & 0.000000 & \\
4 & 0.150546 & & \\
5 & 0.004197 & & \\
6 & 0.000000 & & \\
\hline
\end{tabular}

Table 5 


\begin{tabular}{|c|c|c|c|}
\hline Iterations & Newton's algorithm & New Algorithm-I & New Algorithm-II \\
\hline 0 & 3.000000 & 3.000000 & 3.000000 \\
1 & 2.181402 & 1.452581 & 0.816819 \\
2 & 1.549994 & 0.454100 & 0.000000 \\
3 & 1.045487 & -0.014166 & \\
4 & 0.615469 & 0.000000 & \\
5 & 0.233460 & & \\
6 & 0.016429 & & \\
7 & 0.000005 & & \\
8 & 0.000000 & & \\
\hline
\end{tabular}

Table 6

\section{Conclusion}

In this article we have introduced two new algorithms namely New Algorithm-I and New Algorithm-II for minimization of unconstrained nonlinear functions and comparison made with Newton's algorithm. It is clear from the illustrations that the rate of convergence of the new algorithms are faster than the Newton's algorithm. In future, we extend these new algorithms for minimization of constrained nonlinear functions.

\section{References}

[1] W. Bi, H. Ren, Q. Wu, Three-step iterative methods with eighth-order convergence for solving nonlinear equations, J. Comput. Appl. Math., 225 (2009), 105-112.

[2] C. Chun, Some improvements of Jarratt's method with sixth-order convergence, Appl. Math. Comput., 190 (2007), 1432-1437.

[3] Cope, A two-stage feasible directions algorithm for nonlinear constrained optimization, Mathematical Programming, 36, No. 1 (1986), 19-38.

[4] J.A. Ezquerro, The application of an inverse-free Jarratt-type approximation to nonlinear integral equations of Hammerstein type. Comput. Math. Appl., 36 (1998), 9-20.

[5] L. Hou, X. Li, Twelfth-order method for nonlinear equations, IJRRAS, 3 (2010), 30-36. 
[6] P. Jarratt, Some fourth order multipoint iterative methods for solving equations, Math. Comput., 20, No. 95 (1966), 434-437.

[7] K. Karthikeyan, Some numerical algorithms for minimization of unconstrained optimization problems, Int. Journal of Mathematical Archive, 3, No. 2 (2012), 675-680.

[8] K. Karthikeyan, M. Sundaramurthy, S.K. Khadar Babu, B. Rajesh Anand, New iterative algorithms for minimization of unconstrained nonlinear functions, Bulletin of Pure and Applied Sciences, 31E, No. 1 (2012), 15-23.

[9] J. Kou, Y. Li, X. Wang, An improvement of the Jarratt method, Appl. Math. Comput., 189 (2007), 1816-1821.

[10] Mohan C. Joshi, Kannan M. Moudgalya, Optimization theory and Practice, Narosa Publication House, New Delhi (2004).

[11] Mokhtar S. Bazaraa, Hanif D. Sherali, C.M. Shetty, Non-linear Programming Theory and Algorithms, John Wiley and sons, New York(1993).

[12] B.T. Polyak, Newton's method and its use in optimization, European J. Operational Research, 181, No. 3 (2007), 1086-1096.

[13] X. Wang, J. Kou, Y. Li, A variant of Jarratt method with sixth-order convergence, Appl. Math. Comput., 204 (2008), 14-19.

[14] Young-Ii Kim, Changbum Chun, New twelfth order modifications of Jarratt's method for solving nonlinear equations, Studies in Nonlinear sciences, 1, No. 1 (2010), 14-18. 